\title{
Correction: An insight into circumcised men seeking foreskin reconstruction: a prospective cohort study
}

\section{M. Özer · Floyd W. Timmermans}

Published online: 6 February 2020

(c) The Author(s), under exclusive licence to Springer Nature Limited 2020

\section{Correction to: International Journal of Impotence Research} https://doi.org/10.1038/s41443-019-0223-y

In the published article, Dual Tension Retriever (DTR) should read Dual Tension Restorer. This was an oversight on the part of the authors. Secondly, the sentence "This study resulted one of the first comprehensive overviews on patient-specific motivations and the actions taken towards reconstruction" should read "This study resulted in one of the first comprehensive overviews on patient-specific motivations and the actions taken towards reconstruction". This has been corrected in both the PDF and HTML versions of the Article. 